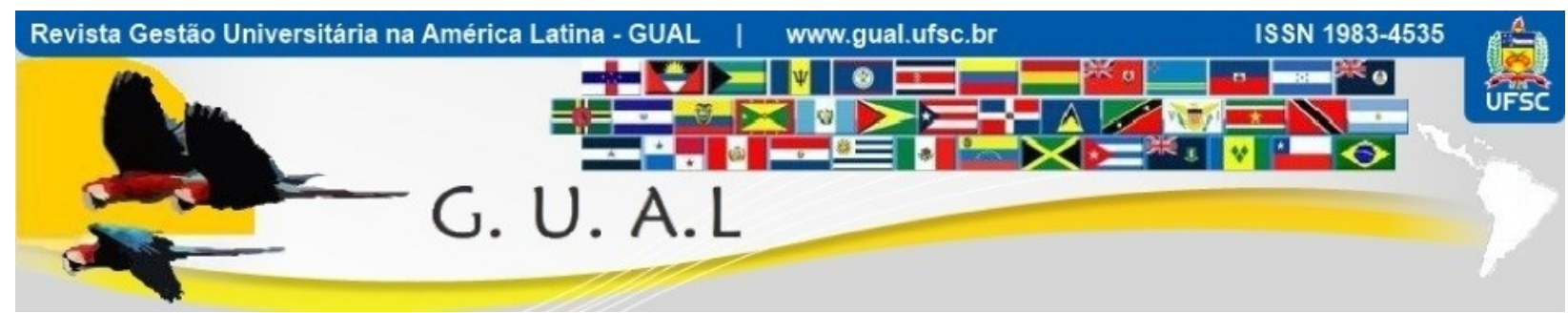

DOI: http://dx.doi.org/10.5007/1983-4535.2019v12n1p228

\title{
A INFLUÊNCIA DOS RECURSOS DIDÁTICOS, DA EQUIPE INSTRUCIONAL E DA AUTOAVALIAÇÃO DISCENTE NOS CURSOS A DISTÂNCIA
}

\section{THE INFLUENCE OF DIDACTIC RESOURCES, INSTRUCTIONAL TEAM AND SELF- ASSESSMENT IN DISTANCE COURSES}

\begin{abstract}
Silvana Silva Vieira Tambosi, Mestre https://orcid.org/0000-0002-4762-7957 profa.silvana.vieira@gmail.com Fundação Universidade Regional de Blumenau | Programa de Pós-Graduação em Ciências Contábeis Blumenau | Santa Catarina | Brasil

Luciano Trentin, Mestre https://orcid.org/0000-0002-7916-3536 trentinluciano@yahoo.com.br Fundação Universidade Regional de Blumenau | Programa de Pós-Graduação em Ciências Contábeis Blumenau | Santa Catarina | Brasil

Maria José Carvalho de Souza Domingues, Doutora https://orcid.org/0000-0001-7771-144X mariadomingues@furb.br Fundação Universidade Regional de Blumenau | Programa de Pós-Graduação em Ciências Contábeis Blumenau | Santa Catarina | Brasil

Iara Regina Parisotto, Doutora https://orcid.org/0000-0002-3162-5826 iaraparisotto@furb.br

Fundação Universidade Regional de Blumenau | Programa de Pós-Graduação em Ciências Contábeis Blumenau | Santa Catarina | Brasil
\end{abstract}

Recebido em 06/março/2017

Aprovado em 22/outubro/2018

Publicado em 02/janeiro/2019

Sistema de Avaliação: Double Blind Review

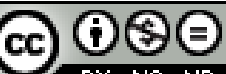

Esta obra está sob uma Licença Creative Commons Atribuição-Uso. 


\title{
RESUMO
}

O ensino a distância é uma modalidade de ensino e aprendizagem que vem ganhando cada vez mais espaço nas instituições de ensino, maior flexibilidade e autonomia. Assim, verificou-se que alguns aspectos deveriam ser ponderados pelas ofertantes desta modalidade, tais como: os recursos didáticos, a equipe instrucional e a autoavaliação discente influenciam o discente de cursos de graduação presencial. Buscando responder à esta questão, realizou-se uma survey descritiva e quantitativa em uma universidade em Santa Catarina, contando com a participação de 196 alunos que cursaram disciplinas na modalidade a distância. Por meio da técnica estatística de regressão logística, descobriu-se que as questões que os estudantes tiveram uma alta percepção estavam relacionadas a dialogicidade do conteúdo produzido pelos professores, as atividades propostas para as disciplinas e os recursos multimídias oferecidos na plataforma. As questões que obtiverem menor observância foram a quantidade de tempo que eles dedicaram para o estudo na modalidade (Autoavaliação), e a atenção/prontidão no retorno dos professores diante dos seus questionamentos (Equipe Instrucional). Como resultado aplicado, sugere-se que instituições ofertantes de ensino na modalidade a distância, invistam nas plataformas virtuais de ensino, recursos multimídias e na produção do conteúdo didático, a fim de satisfazer as necessidades de aprendizagem do estudante.

Palavras-chave: Modalidade a Distância. Recursos Didáticos. Autovaliação. Equipe Instrucional.

\begin{abstract}
Distance learning is a type of teaching and learning that has been growing in educational institutions, greater flexibility and autonomy. However, it was found that some aspects should be considered by the providers of this modality: the didactic resources, instructional team and the student self-assessment influences the student of undergraduate courses. In order to answer this question, a survey was applied, descriptive and quantitative in a university in Santa Catarina, with the participation of 196 students who studied subjects in the distance learning. Using the statistical technique of logistic regression, it was found that the questions that the students had a high perception were related to the dialogicity of the content produced by the teachers, the proposed activities for the subjects and the multimedia resources offered in the platform. The issues that were least observed were the amount of time they devoted to the study in the modality (student self-assessment), and the attention / readiness in the teachers' return to their questions (instructional team). As an applied result, it is suggested that institutions providing distance learning, invest in virtual educational platforms, multimedia resources and in the production of didactic content, in order to satisfy the learning needs of the student.
\end{abstract}

Keywords: Distance learning. Didactic Resources. Student Self-Assessment. Instructional Team. 


\section{INTRODUÇÃO}

A oferta de ensino por meio da educação a distância (EAD) movimenta o mercado, o qual investe em cursos nessa modalidade em todo território nacional (HADDAD; GRACIANO, 2004; MANCEBO et al., 2015). Nesse contexto, a EAD, torna-se um tema pertinente para pesquisas, pois o crescimento desta modalidade incita as instituições educacionais a estruturar as áreas administrativas e tecnológicas, para que haja interatividade entre docentes, discentes e colaboradores, exigindo destaque para a qualidade do ensino e aprendizagem (BOAS et al. 2011).

O crescimento do Ensino Superior (ES) na modalidade de Educação a Distância (EAD) no Brasil se mostra rápido. Em 2015, mais de cinco milhões de brasileiros realizaram cursos nesta modalidade segundo o Anuário Estatístico de Educação Aberta e a Distância no Brasil (ABED, 2015). Contabilizando 5.048.912 alunos de EAD, com 1.108.021 em cursos regulamentados por nível acadêmico totalmente a distância e semipresenciais, e 3.940.891 em cursos livres ou corporativos. Foram registrados 1.180.296 a mais que o ano anterior. Em cursos técnicos, de graduação e pós-graduação lato sensu são ofertados integralmente no formato EAD mais de 1.100.000 estudantes (ABED, 2015).

Mediante os dados, Montiel et al. (2014) ressaltam que a modalidade da educação a distância (EAD), inicialmente surgiu para suprir as deficiências de alcance do sistema de ensino convencional. Os autores ainda destacam que atualmente a modalidade de ensino se mostra capaz de complementar o sistema regular de ensino presencial, apoiando-se em práticas pedagógicas modernas e em recursos tecnológicos que facilitam a comunicação entre professor e aluno, ultrapassando limites de tempo e distância.

Alves (2011) acrescenta que a educação a distância é uma das modalidades educacionais mais democráticas, pois utiliza as tecnologias tanto da informação quanto de comunicação em prol da conquista do conhecimento atendendo um grande número de pessoas simultaneamente.

Para se estabelecer as contribuições específicas desta modalidade de ensino para a educação e a qualidade desta, torna-se necessário aplicar sistemas de avaliações para identificar aspectos a serem melhorados. No que tange a avaliação na EAD, SEED/MEC (2003) destaca que

Cursos e programas a distância, pelo seu caráter diferenciado e pelos desafios que enfrentam, devem ser acompanhados e avaliados em todos os seus aspectos, de forma sistemática, contínua e abrangente. Duas dimensões 


\section{A INFLUÊNCIA DOS RECURSOS DIDÁTICOS, DA EQUIPE INSTRUCIONAL E DA AUTOAVALIAÇÃO \\ DISCENTE NOS CURSOS A DISTÂNCIA \\ DOI: http://dx.doi.org/10.5007/1983-4535.2019v12n1p228}

devem ser contempladas na proposta de avaliação: (1) a que diz respeito ao aluno e (2) a que se refere ao curso como um todo, incluindo os profissionais que nele atuam (BRASIL, 2003, s/p).

Autores como Vitorino (2014), Zerbini e Abbad (2008), afirmam a necessidade de ações para avaliar e desenvolver ferramentas que descrevam estratégias e competências envolvidas nas instituições de ensino. Corroborando com os autores, Marchesan e Souza (2006) anunciam a importância do processo avaliativo nas Instituições de Ensino Superior (IES), pois por meio deste processo as instituições poderão verificar o quanto estão comprometidas com a construção de uma educação de qualidade.

Para uma educação de qualidade na EAD, destaca-se a importância da avaliação das dimensões didático pedagógica, pois esta orienta o processo educativo, podendo inferir diretamente na aprendizagem do aluno e influenciar na sua decisão em estudar novamente na modalidade a distância. Em SEED/MEC (2017) ressalta-se que os referenciais de qualidade na modalidade, incluem os aspectos pedagógicos, recursos humanos e infraestrutura. Para se atingir estes aspectos tornam-se essenciais a avaliação da concepção de educação e currículo no processo de ensino e aprendizagem, sistemas de comunicação, material didático, avaliação, equipe multidisciplinar, infraestrutura de apoio, gestão acadêmico-administrativa (SEES/MEC, 2017).

Neste contexto, a presente pesquisa tem como objetivo verificar se os recursos didáticos, a equipe instrucional e a autoavaliação discente influenciam na sua decisão em estudar novamente na modalidade a distância.

O documento está estruturado da seguinte forma: a primeira seção fundamenta a teoria do assunto abordado, a segunda apresenta os métodos usados na pesquisa, a terceira discute os resultados encontrados no estudo e por último, as considerações finais e as recomendações para trabalhos futuros.

\section{FUNDAMENTAÇÃO TEÓRICA}

Neste capítulo são apresentados os aportes teóricos desta pesquisa sobre a educação a distância e a dimensões didático pedagógicas, os quais servirão de base para a discussão dos resultados. 


\subsection{MODALIDADE DA EDUCAÇÃO A DISTÂNCIA}

A educação a distância alavancou o Ensino Superior no país, levando a possibilidade de graduação aos lugares mais distantes, contribuindo com a democratização do ensino no Brasil. No entanto cabe destacar que esta modalidade emergiu amparada pelas novas Tecnologias de Informação e Comunicação (TICs). Belloni (2002) ao fazer reflexões sobre o conceito que abarca a modalidade anuncia que,

o conceito de distância está se transformando, como as relações de tempo e espaço, em virtude das incríveis possibilidades de comunicação a distância que as tecnologias de telecomunicações oferecem. Também o conceito de interatividade carrega em grande ambiguidade, oscilando entre um sentido mais precioso de virtualidade técnica e um sentido mais amplo de interação entre sujeitos, mediatizada pelas máquinas (BELLONI, 2002, p. 1).

Mediante a definição, compreende-se que a EAD, necessita promover o relacionamento entre as partes e o todo, ocasionando um entrelaçamento interdependente de pessoas e atividades no ambiente de trabalho, abarcando a efetivação da aprendizagem do estudante e sua formação, ou seja, o desenvolvimento pleno das competências cognitivas sociais e efetivas (MARCHETI et al. 2005).

No que tange a organização da modalidade, Marcuzzo et al. (2015) destacam que contrário ao ensino presencial, na modalidade EAD, não há uma organização e estruturação definida, existindo situações educativas que podem suprimir qualquer um dos elementos característicos do modelo presencial, como espaço, tempo, conteúdo, presença, etc. Sobre a flexibilidade metodológica da EAD, Marcheti et al. (2005), ressaltam que esta permite ao docente uma revisão da estrutura do ensino a favor da aprendizagem, colocando os estudantes como corresponsáveis pela qualidade do processo educacional no qual se encontram inseridos.

No contexto dessa modalidade, o monitoramento da aprendizagem acontece com maior intensidade pelo aluno, o qual possui menor dependência do professor. No entanto a comunicação entre estes é mediada por materiais impressos, digitais e/ou pelas tecnologias de informação e comunicação (TAROUCO, 1999; HENRY; MEADOWS, 2008).

Dentre as tecnologias digitais de informação e comunicação, Schenatz e Borges (2013) destacam o vídeo e a internet, os quais permitem ao professor aprimorar suas metodologias de ensino, facilitando e incentivando a aprendizagem, ao mesmo tempo em que aproximam os alunos, evitando que eles se sintam meros receptores de conteúdos, mas sim, participantes 
ativos na construção do conhecimento. As autoras ainda mencionam os Ambientes Virtuais de Aprendizagem (AVA), os chats, wikis, fóruns de discussão, disponibilização de hipertextos e vídeos, os quais propiciam aos alunos condições diversas para a aprendizagem (SCHENATZ; BORGES, 2013).

Com vistas a complexidade que envolve a modalidade, os referencias de qualidade para os cursos devem incluir os seguintes aspectos: pedagógicos, recursos humanos e infraestrutura. Para atender estes aspectos, torna-se essencial a análise dos seguintes tópicos: concepção de educação e currículo no processo de ensino e aprendizagem, sistemas de comunicação, material didático, avaliação, equipe multidisciplinar, infraestrutura de apoio, gestão acadêmico-administrativa e sustentabilidade financeira (SEED/MEC, 2017).

As dimensões a serem consideradas pelos cursos EAD, são: organização pedagógica de aprendizagem dos estudantes, práticas educacionais dos professores e tutores, material didático, tecnologias de informação e comunicação, currículo, sistema de orientação docente para o atendimento aos estudantes (SEED/MEC, 2017). As tecnologias de informação e comunicação podem ser consideradas ideais para atender as necessidades educacionais dos professores e alunos, ao serem apoiadas pela rápida resposta do tutor aos e-mails e atividades (HOPPER; HARMON, 2000); estabelecendo compromisso e feedback individual (ANDERSON, 2006); especificando os objetivos (CARR-CHELLMAN; DUCHASTEL, 2000; SIEBER, 2005), detalhando o suficiente para esclarecer o que o aluno pode realizar e as condições em que os alunos esperam produzir (ELLIS; HAFNER, 2003), se tornando importante meio de comunicação (WHITE, 2000).

As dimensões que envolvem a avaliação na EAD tornam-se um importante fator para propiciar um elo entre discentes e a IES. Deste modo torna-se basilar que as instituições de ensino conheçam por meio da avaliação: o perfil dos discentes e as suas necessidades, para que se possa ofertar serviços de qualidade, contribuindo para melhores resultados na instituição e para a retenção dos discentes.

No que tange os recursos didáticos, torna-se pertinente destacar que o advento das tecnologias de informação e comunicação (TICs), guiam a novas perspectivas para o ensino na modalidade a distância. Segundo Beckhauser e Domingues (2017) as TICs são formadas por recursos digitais que permitem a exposição de materiais por meio de vídeos, hipertextos e páginas virtuais, os quais possibilitam combinar a flexibilidade da interação humana com a 


\section{A INFLUÊNCIA DOS RECURSOS DIDÁTICOS, DA EQUIPE INSTRUCIONAL E DA AUTOAVALIAÇÃO

independência de tempo e de espaço, gerando diversas mudanças na área educacional tanto pelo seu emprego em cursos presenciais quanto pela maior difusão da educação a distância.

Possolli et al. (2009) evidenciam ainda que os recursos didáticos para EAD configuram-se como um conjunto de mídias (impresso, audiovisual e informáticos), no qual os conteúdos apresentam-se de forma dialógica e contextualizada, favorecendo uma aprendizagem significativa. Nessa perspectiva compreende-se que quanto mais diversificado o material, "torna-se maior a proximidade das diferentes realidades dos educandos, o que possibilita diferentes formas de interagir com o conteúdo" (FLEMING, 2004, p. 23). Aspecto este, considerado fundamental para garantir impacto positivo na oferta da EAD (ALMRASHDEH et al., 2011; BERDROW E EVERS, 2010), pois a aprendizagem na modalidade acontece em salas de aula virtuais (VARGAS; SOLÍS; ESPINOSA; OLIVARES, 2016).

No entanto, cabe destacar que alguns aspectos podem vir a contribuir para a desmotivação dos discentes, sendo eles: a desorganização no planejamento e na apresentação de um material multimídia, e a inadequação na utilização de ferramentas disponíveis em um ambiente virtual de aprendizagem (TAMBOSI; BORGES; DOMINGUES, 2014).

Assim entende-se que as especificidades que abarcam os recursos didáticos na EAD necessitam garantir o uso das mídias, a autonomia, a interatividade e a dialogicidade, propiciando uma aprendizagem contextualizada de acordo com o público-alvo e com os objetivos do curso, pois a qualidade dos recursos didáticos também podem influenciar o discente a fazer outro curso ou disciplina na modalidade a distância. Corroboram com esta ideia, Pinho (2008); Souza et al. (2011); Bernardes (2012); Vidal e Mercado (2014).

Diante do anunciado, considera-se pertinente destacar que os referenciais de qualidade para EAD propostos pela SEED/MEC (2017), possibilitam inferir que as dimensões de avaliação apresentadas na seqüência são as mais relevantes, quando se busca verificar se os recursos didáticos, a equipe instrucional e a autoavaliação discente influenciam na sua decisão em estudar novamente na modalidade a distância.

\subsection{DIMENSÕES DE AVALIAÇÃO NA EAD}

a) Recursos Didáticos

A seleção e elaboração dos recursos didáticos no processo de ensino e aprendizagem são aspectos de extrema importância na modalidade, pois a EAD, requer um conjunto de 
materiais acessíveis que despertem o interesse dos alunos e contemplem os diferentes estilos de aprendizagem (SARMENTO et al. 2008). As autoras ainda destacam que os materiais necessitam ter qualidade, e estar em conformidade com a proposta pedagógica, atendendo as especificidades e características de cada disciplina. Segundo o documento SEED/MEC (2007, p.13) a produção de

material impresso, vídeos, programas televisivos e radiofônicos, videoconferências, CD-Rom, páginas WEB, objetos de aprendizagem e outros, para uso a distância, atende a diferentes lógicas de concepção, produção, linguagem, estudo e controle de tempo. Para atingir estes objetivos, é necessário que os docentes responsáveis pela produção dos conteúdos trabalhem integrados a uma equipe multidisciplinar especialistas em desenho instrucional, diagramação, ilustração, desenvolvimento de páginas web, entre outros (BRASIL, 2007, p.13).

Ainda sobre os recursos didáticos, cabe destacar as tecnologias de informação e comunicação (TICs), as quais norteiam a novas perspectivas para o ensino na modalidade. As TICs são constituídas por recursos digitais que permitem a exposição de materiais por meio de vídeos, hipertextos e páginas virtuais, os quais possibilitam combinar a flexibilidade da interação humana com a independência de tempo e de espaço. (BECKHAUSER; DOMINGUES, 2017)

Possolli et al. (2009) acrescenta que os recursos digitais necessitam apresentar-se de forma dialógica e contextualizada, favorecendo uma aprendizagem significativa com proximidade das diferentes realidades dos alunos, possibilitando diferentes formas de interagir com o conteúdo.

Corroborando com o destacado, Mallmann e Catapan (2007, p.64) ressaltam que a produção do material didático na modalidade prevê grande parte das estratégias pedagógicas, as quais são elaboradas por uma equipe de profissionais, que garantem otimizar a produção destes, para orientar o processo de ensino-aprendizagem de forma mais autônoma, cooperativa e interativa.

b) Equipe Instrucional

A dinâmica da EAD se constitui pelo trabalho de uma equipe multidisciplinar, a qual se faz presente no desenvolvimento dos materiais e na implementação do curso. Segundo SEED/MEC (2007) a equipe multidisciplinar tem como funções o planejamento, a implementação e gestão dos cursos, devendo ser constituída por docentes, tutores e pessoal 
técnico-administrativo. Essa equipe de acordo com Mallmann e Catapan (2007, p.64) "se faz necessária desde a elaboração dos materiais até a avaliação”.

O documento da Secretaria de Educação a Distância anuncia que os docentes têm como função: a) estabelecer os fundamentos teóricos do projeto; b) selecionar e preparar todo o conteúdo curricular articulado a procedimentos e atividades pedagógicas; c) identificar os objetivos referentes a competências cognitivas, habilidades e atitudes; d) definir bibliografia, videografia, iconografia, audiografia, tanto básicas quanto complementares; e) elaborar o material didático para programas a distância; f) realizar a gestão acadêmica do processo de ensino-aprendizagem, em particular motivar, orientar, acompanhar e avaliar os estudantes (SEED/MEC, 2007).

Os tutores necessitam ser compreendidos como sujeitos que participam ativamente da prática pedagógica, pois suas atividades contribuem para o desenvolvimento dos processos de ensino e de aprendizagem, proporcionando alternativas de interação "para cada momento de aprendizagem que se fará autônomo, individual ou em grupos de estudantes" (MALLMANN e CATAPAN, 2007, p. 65).

Segundo SEED/MEC (2007) o tutor a distância tem como principal função "o esclarecimento de dúvidas através fóruns de discussão pela Internet, pelo telefone, participação em videoconferências, entre outros, de acordo com o projeto pedagógico" (BRASIL, 2007, p.21).

A tutoria presencial, de acordo com o documento, atende os alunos nos pólos em horários pré-estabelecidos. Este profissional necessita conhecer o projeto pedagógico do curso, o material didático e o conteúdo específico dos conteúdos sob sua responsabilidade, a fim de auxiliar os estudantes no desenvolvimento de suas atividades individuais e em grupo, fomentando o hábito da pesquisa, esclarecendo dúvidas em relação a conteúdos específicos, bem como ao uso das tecnologias disponíveis. O tutor presencial deve manter-se em permanente comunicação tanto com os estudantes quanto com a equipe pedagógica do curso (SEED/MEC, 2007).

Ao encontro do destacado pelo documento, cabe destacar que o tutor difere do professor, porque o tutor busca caminhos para facilitar o processo de ensino-aprendizagem, ou seja, não cabe a ele ministrar aulas mas sim criar condições para que os alunos construam seu conhecimento com autonomia. O professor transmite os conteúdos, e o tutor reforça o processo de auto-aprendizagem dos alunos de forma on-line exercendo função de facilitador e 
mediador de aprendizagem consistindo em promover a familiarização do aluno com a metodologia do curso e o material didático (SPUDEIT; VIAPIANA; VITORINO, 2010).

\section{c) Autoavaliação}

Frente as especificidades que constituem a EAD, considera-se que esta modalidade demanda de instrumentos e estratégias diferenciadas da educação presencial. Neste contexto, Amaral et al. (2009) salienta que a avaliação na EAD, necessita permitir o exercício de novas funções e delegando autonomia, a medida que circunda instrumentos de avaliação e de autoavaliação.

A autoavaliação de acordo com Andrade e Ying Du (2007) se constitui em um processo do qual os alunos refletem e avaliam a qualidade do trabalho, refletindo os pontos fortes e fracos. Pontos estes, os quais Ross (2006) destaca como essenciais para melhorar os resultados da aprendizagem.

Nunes (2012) destaca a autoavaliação como imprescindível na EAD, pois a aprendizagem nesta modalidade ocorre por meio das atividades discentes realizadas em seu ambiente de estudo. No entanto, cabe destacar que a autoavaliação necessita de reflexões que venham gerar respostas que reduzam a complexidade e a subjetividade que a abarca, servindo de "bússola para a aquisição do conhecimento e para as competências estabelecidas nos planos de formação" (PRIMO, 2008, p.64).

Para além de um instrumento utilizado para a orientação, a autoavaliação necessita ser compreendida como uma ferramenta em que o discente avalia de forma crítica suas atitudes, e como estas veem contribuindo para a construção do conhecimento. Neste sentido Fabricio et al. (2011, p.5) aponta que a autoavaliação pode ter como alicerce a "assiduidade, pontualidade, participação, relacionamento e seu interesse pela disciplina”.

No entanto, os principais objetivos da autoavaliação são os de impulsionar a aprendizagem promovendo a auto-regulação acadêmica, ou a tendência de monitorar e gerenciar a própria aprendizagem. (PINTRICH, 2000; ZIMMERMAN; SCHUNK, 2004; ANDRADE; VALTCHEVA, 2009).

Ao encontro do anunciado pelos autores Punhagui e Souza (2012, p.203) destacam que a autoavaliação, permite que "os alunos pensem a respeito de como estão em relação à sua aprendizagem. Afinal, o processo autoavaliativo tem o intuito de promover o reconhecimento dos passos dados e, consequentemente, o planejamento daqueles que ainda estão por vir". 


\section{A INFLUÊNCIA DOS RECURSOS DIDÁTICOS, DA EQUIPE INSTRUCIONAL E DA AUTOAVALIAÇÃO

As autoras ainda acrescentam que a autoavaliação precisa ser compreendida como uma atividade que permite a análise do processo de aprendizagem e o feedback como parte de todo o processo. No entanto o que importa é que esta esteja alicerçada em questões que envolvam a autonomia e a comunicação na EAD, pois estas bases norteiam a avaliação e fornecem dados para discussões sobre o processo que envolvem a modalidade (PRIMO, 2008).

\section{METODOLOGIA}

A fim de responder o objetivo deste estudo, que foi verificar se os recursos didáticos, a equipe instrucional e a autoavaliação discente influenciam na sua decisão em estudar novamente na modalidade a distância, utilizou-se uma abordagem qualitativa para a elaboração do instrumento de coleta de dados e quantitativa. A abordagem quantitativa objetiva a mensuração de fenômenos, compreendendo a coleta e a análise de dados numéricos (quantitativos), e realizando testes estatísticos. O fator relevante para a validação de estudos quantitativos é facultado por meio da confiabilidade dos indicadores estatísticos (COLLIS; HUSSEY, 2013).

A definição das questões elaboradas ocorreu por meio da técnica qualitativa exploratória (focus group) composta por três servidores técnicos e cinco professores de uma universidade no estado Santa Catarina que oferta disciplinas na modalidade a distância para os graduandos de seus cursos presenciais. A necessidade de realizar uma focus group deu-se a necessidade da Instituição de Ensino, ofertante de disciplinas na modalidade a distância, saber de seus estudantes como eles avaliavam os recursos didáticos elaborados para a disciplina e como eles se avaliavam estudando nesta nova modalidade, uma vez que tratam-se de cursantes regulares de cursos presenciais. Assim, procurou-se conhecer os elementos que fazem parte dos recursos didáticos desta modalidade de ensino. Identificou-se 16 itens que foram agrupados em três dimensões: "recursos didáticos", "equipe instrucional" e "autoavaliação do estudante" (descritas no Quadro 1). Estas serviram como base para a elaboração de um questionário fechado e estruturado, validado por três doutorandos em administração, pesquisadores sobre a temática. Para a mensuração das questões, utilizou-se escala de likert de 5 pontos, sendo 1 atribuído a discordância total do respondente e 5 a concordância total do respondente com as afirmativas que compuseram as questões. 
Quadro 1 Dimensões e indicadores que compõem o instrumento de coleta de dados

\begin{tabular}{|l|l|}
\hline \multicolumn{1}{|c|}{ Dimensões } & \multicolumn{1}{|c|}{ Fatores que compõem a dimensão } \\
\hline \multirow{4}{*}{ Perfil dos respondentes } & Q1 - Idade \\
\cline { 2 - 3 } & Q2 - Gênero \\
\hline & Q3 - Dialogicidade do material didático. \\
\cline { 2 - 3 } & $\begin{array}{l}\text { Q4 - Atividades de aprendizagem: fóruns, quiz, avaliações, } \\
\text { leituras permitiram o aprofundamento das temáticas } \\
\text { trabalhadas na disciplina. }\end{array}$ \\
\cline { 2 - 3 } & $\begin{array}{l}\text { Q5 - A importância da Webconferência como ferramenta } \\
\text { para a disciplina. }\end{array}$ \\
\cline { 2 - 3 } Recursos didáticos & $\begin{array}{l}\text { Q6 - A importância dos recursos multimídia para a } \\
\text { aprendizagem do estudante. }\end{array}$ \\
\cline { 2 - 3 } & $\begin{array}{l}\text { Q7 - Atividades propostas possibilitaram a interação entre } \\
\text { os estudantes e contribuíram para a aprendizagem. }\end{array}$ \\
\cline { 2 - 3 } & $\begin{array}{l}\text { Q8 - Quantidade de conteúdo e atividades oferecidas na } \\
\text { disciplina. }\end{array}$ \\
\cline { 2 - 3 } & $\begin{array}{l}\text { Q9 - As atividades na modalidade EAD motivaram os } \\
\text { estudantes a ler e pesquisar mais sobre o conteúdo. }\end{array}$ \\
\cline { 2 - 3 } & $\begin{array}{l}\text { Q10 - Layout: aspectos visuais e acesso aos materiais } \\
\text { (navegabilidade na plataforma), atividades do Ambiente }\end{array}$ \\
& Virtual de Aprendizagem. \\
\hline \multirow{5}{*}{ Equipe Instrucional } & $\begin{array}{l}\text { Q11 - Atenção e prontidão do professor em orientar os } \\
\text { alunos diante de dúvidas e questionamento do aluno. }\end{array}$ \\
\cline { 2 - 3 } & $\begin{array}{l}\text { Q12 - Contribuição do retorno/respostas do professor para } \\
\text { a compreensão do conteúdo. }\end{array}$ \\
\cline { 2 - 3 } & Q13 - Atendimento da equipe de monitoria. \\
\hline \multirow{2}{*}{ Autoavaliação } & Q14 - Dedicação a disciplina. \\
\cline { 2 - 3 } & Q15 - Quantidade de tempo de estudo. \\
\hline
\end{tabular}

Fonte: Dados da pesquisa qualitativa exploratória.

A população foi composta por 196 graduandos de cursos regularmente presenciais de uma universidade no estado Santa Catarina, que cursaram disciplinas na modalidade a distância desta mesma instituição, no final dos semestres acadêmicos, ou seja, nos meses de julho e novembro dos anos de 2015 e 2016 . Em seguida os dados foram tabulados em planilha do software Microsoft Excel ${ }^{\circledR}$ e importados para o software Estatístico SPSS ${ }^{\circledR}$ (Statistical Package for the Social Sciences) versão 22.

Com relação a técnica estatística, utilizada para o tratamento e análise dos dados, utilizou-se a pesquisa descritiva, indicada para o detalhamento de situações específicas, em que é desenvolvida e estruturada para mensurar as características das ocorrências encontradas em um estudo científico (HAIR Jr et. al., 2009). Aplicou-se também a regressão logística. Esta técnica de análise multivariada é utilizada para explicar ou predizer a ocorrência de determinado evento em função de um conjunto de variáveis preditoras (FÁVERO et al., 2009). 
A partir do instrumento e do referencial teórico foram constituídas três hipóteses, que foram testadas empiricamente, sendo que o modo como isto ocorreu é apresentado a seguir:

$\mathrm{H}_{1}:$ Os recursos didáticos em uma disciplina cursada na modalidade a distância influenciam positivamente na sua decisão de cursar uma nova disciplina ou curso nesta modalidade.

$\boldsymbol{H}_{2:}$ A atuação da equipe instrucional em uma disciplina cursada na modalidade a distância influenciam positivamente na sua decisão de cursar uma nova disciplina ou curso nesta modalidade.

$\boldsymbol{H}_{3:}$ A autoavaliação do discente em uma disciplina cursada na modalidade a distância influência positivamente na sua decisão de cursar uma nova disciplina ou curso nesta modalidade.

Para que as hipóteses pudessem ser testadas, as dimensões pesquisadas foram comparadas com o interesse do aluno em cursar novamente uma disciplina na modalidade a distância (Q16), esta, medida de forma dicotômica: "sim" ou "não". Após a descrição dos procedimentos metodológicos utilizados para o desenvolvimento da pesquisa, em seguida apresenta-se as análises dos resultados encontrados.

\section{ANÁLISE DOS DADOS}

Nesta seção são apresentados e analisados os resultados da pesquisa. O primeiro teste estatístico realizado foi o teste de confiabilidade Alfa de Cronbach (Tabela 1). Segundo Hair Jr. et al. (2009) este indicador faz a mensuração da confiabilidade em uma variância de 0 a 1 , sendo os valores de 0,60 a 0,70 considerados o limite inferior de aceitabilidade. Nesta pesquisa os valores foram 0,81 (Dimensão 1) e 0,75 (Dimensão 2), considerando boa confiabilidade dos dados.

Tabela 1 Análise de Confiabilidade

\begin{tabular}{cc}
\hline Dimensões & Alfa de Cronbach \\
\hline Dimensão 1 & 0,81 \\
Dimensão 2 & 0,75 \\
\hline
\end{tabular}

Fonte: Dados da pesquisa.

Em seguida (Tabela 2) foi realizada uma análise descritiva, em que é apresentado o resultado das dimensões pesquisadas. 
Tabela 2 Resultado das questões propostas nas dimensões

\begin{tabular}{|c|c|c|c|c|c|}
\hline \multirow{5}{*}{ Perfil dos respondentes } & \multirow{2}{*}{$\begin{array}{l}\text { Idade (Q1) } \\
17 \text { a } 20 \text { anos }\end{array}$} & \multirow{2}{*}{ Percentual } & \multirow{2}{*}{ Gênero (Q2) } & \multicolumn{2}{|c|}{ Percentual } \\
\hline & & & & \\
\hline & 21 a 24 anos & $26,5 \%$ & Feminino & \multicolumn{2}{|c|}{56,1} \\
\hline & & $15,5 \%$ & & \multirow{2}{*}{\multicolumn{2}{|c|}{$43,9 \%$}} \\
\hline & 30 a 34 anos & $7,7 \%$ & Masculino & & \\
\hline Dimensões & Questões & Mínimo & Máximo & Média & $\begin{array}{l}\text { Desvio } \\
\text { padrão }\end{array}$ \\
\hline \multirow{8}{*}{ D1 - Recursos didáticos } & Q3 & 1 & 5 & 4,46 & 0,754 \\
\hline & Q4 & 1 & 5 & 4,10 & 0,926 \\
\hline & Q5 & 1 & 5 & 3,67 & 1,121 \\
\hline & Q6 & 1 & 5 & 4,15 & 0,904 \\
\hline & Q7 & 1 & 5 & 3,67 & 1,070 \\
\hline & Q8 & 1 & 3 & 2,74 & 0,553 \\
\hline & Q9 & 1 & 5 & 3,40 & 1,187 \\
\hline & Q10 & 1 & 3 & 2,23 & 0,946 \\
\hline \multirow{3}{*}{ D2 - Equipe Instrucional } & Q11 & 1 & 3 & 2,23 & 0,948 \\
\hline & Q12 & 1 & 5 & 2,94 & 1,659 \\
\hline & Q13 & 1 & 5 & 3,88 & 1,040 \\
\hline \multirow{2}{*}{ D3 - Autoavaliação } & Q14 & 1 & 5 & 3,80 & 0,757 \\
\hline & Q15 & 1 & 5 & 1,92 & 0,793 \\
\hline
\end{tabular}

Fonte: Dados da pesquisa.

$\mathrm{Na}$ Tabela 2, quanto ao perfil dos respondentes, a maioria (70,9\%) são jovens com idades entre 17 e 24 anos, e do sexo feminino $(56 \%, 1)$. Quanto as dimensões propostas neste estudo, pode-se observar, por meio da média das questões que compõem as dimensões (Recursos didáticos; Equipe Instrucional; Autoavaliação), que os estudantes tiveram uma alta percepção quanto a dialogicidade do conteúdo produzido pelos professores, as atividades propostas para as disciplinas e os recursos multimídias oferecidos na plataforma. As questões que obtiverem menor observância dos acadêmicos foram a quantidade de tempo que eles dedicaram para o estudo na modalidade (dedicaram pouco tempo) e a atenção/prontidão no retorno dos professores diante dos seus questionamentos.

Tabela 3 Processamento do modelo e significância

\begin{tabular}{ccccc}
\hline \multicolumn{1}{c}{ Casos } & $\mathbf{N}$ & Porcentagem & \multicolumn{2}{c}{ Q16 } \\
\hline $\begin{array}{c}\text { Incluído na análise } \\
\text { Casos ausentes }\end{array}$ & 196 & 100,0 & Sim & Não \\
& 0 & 0 & 157 & 39 \\
\hline B & Variáveis na equação & & Exp(B) \\
\hline$-1,393$ & 0,179 & Wald & Sig. & 0,248 \\
\hline
\end{tabular}

Fonte: Dados da pesquisa. 
Conforme apresentado na Tabela 3, todos os 196 casos foram ponderados (100\%) para a análise da pesquisa, destes 157 estudantes responderam que cursariam novamente uma disciplina na modalidade a distância, e 39 responderam que não cursariam. Avaliou-se também a significância da constante incluída no modelo (S.E), que é significativa pois apresentou valor diferente de zero (CORRAR, 2007; FÁVERO, 2009).

Tabela 4 Testes de coeficientes do modelo Omnibus

\begin{tabular}{|c|c|c|c|c|c|}
\hline $\begin{array}{c}\text { Qui- } \\
\text { quadrado }\end{array}$ & Df & Sig. & $\begin{array}{c}\text { Verossimilhança } \\
\text { de log }-2\end{array}$ & $\begin{array}{l}\text { R quadrado } \\
\text { Cox \& Snell }\end{array}$ & $\begin{array}{l}\text { R quadrado } \\
\text { Nagelkerke }\end{array}$ \\
\hline 69,764 & 9 &, 000 & & & \\
\hline 69,764 & 9 & 000 & $125,838 a$ & 0,299 & 0,474 \\
\hline 69,764 & 9 &, 000 & & & \\
\hline
\end{tabular}

Fonte: Dados da pesquisa.

Por meio da Tabela 4 foi realizado o teste Qui-quadrado, que objetivou testar a hipótese de que todos os coeficientes da equação logística eram nulos, apresentando o valor 69,764 para o modelo. Também foi calculado o grau de liberdade (df), apresentando coeficientes de regressão diferentes de zero. Portanto pode-se rejeitar a hipótese que todos os parâmetros estimados são nulos. Ou seja, verificou-se que eles contribuem para melhorar a qualidade da variável preditora (CORRAR; PAULO; DIAS FILHO, 2007; FÁVERO, 2009).

Ainda, conforme apresentado na Tabela 4, o R quadrado Cox \& Snell indicou que 29,9\% das variações ocorridas no $\log$ da razão de chance são explicadas pelo conjunto das variáveis independentes (dimensões: recursos didáticos, equipe instrucional e autoavaliação do estudante). No teste de R quadrado de Nagelkerke, que para ser considerado satisfatório deve apresentar resultados entre 0 e 1 . Por essa medida, pode-se considerar que o modelo é capaz de explicar cerca de $47,4 \%$ das variações registradas na variável dependente (FÁVERO, 2009).

Tabela 5 Teste de Hosmer e Lemeshow e Classificação global

\begin{tabular}{cccc}
\hline Qui-quadrado & Df & Sig. & Classificação \\
\hline 8,287 & 8 & 0,406 & 88,8 \\
\hline
\end{tabular}

Fonte: Dados da pesquisa.

De acordo com a Tabela 5, não há diferenças significativas entre os resultados preditos (Q16) pelo modelo e os observados, classificando-o corretamente em 88,8\%. Assim, o modelo pode ser utilizado para estimar a probabilidade de um determinado estudante, que já 
cursou uma disciplina na modalidade de ensino a distância, a tornar-se novamente um cursante desta modalidade em função das variáveis independentes presentes nas dimensões "recursos didáticos"; "equipe instrucional" e "autoavaliação".

Os resultados deste estudo corroboram com os de Tambosi; Borges; Domingues (2014) e de Beckhauser e Domingues (2017) os quais concluíram que a dedicação e aprendizado do aluno, (dimensões estas que envolvem a autoavaliação) e a qualidade de acessibilidade da disciplina (aspectos que estão relacionados aos recursos didáticos) influenciam na decisão em cursar novamente uma disciplina na modalidade semipresencial.

Sobre os recursos didáticos na EAD abordado neste estudo, vale ressaltar que Beckhauser e Domingues (2017) também encontraram evidências de que a qualidade dos recursos didáticos (vídeos, hipertextos, páginas virtuais, etc.) influenciam na decisão em cursar novamente uma disciplina na modalidade semipresencial. Compreende-se que os recursos influenciam na decisão dos discentes, por facilitarem e incentivarem o aprendizado e ao mesmo tempo tornarem os discentes ativos na construção do conhecimento (SCHENATZ e BORGES, 2013), favorecendo uma aprendizagem significativa (POSSOLI et al. 2009).

Assim sendo, cabe destacar que as questões que obtiverem menor observância dos discentes foram a quantidade de tempo que eles dedicaram para o estudo na modalidade (dedicaram pouco tempo) e a atenção/prontidão no retorno dos professores diante dos seus questionamentos. Essas dimensões apresentam-se como fatores não relevantes na decisão do discente em cursar uma nova disciplina ou curso nesta modalidade.

\section{CONSIDERAÇÕES FINAIS}

O presente estudo teve como objetivo verificar se os recursos didáticos, a equipe instrucional e a autoavaliação discente influenciam na sua decisão em estudar novamente na modalidade a distância. Os sujeitos da pesquisa foram graduandos que cursaram disciplinas na modalidade a distância em uma IES localizada no Estado de Santa Catarina.

Mediante resultados, constatou-se que das variáveis investigadas, a dedicação e o aprendizado do aluno, (dimensões estas que envolvem a autoavaliação) e aspectos que tangem a clareza quanto a dialogicidade, a organização do conteúdo produzido pelos professores, as atividades propostas para as disciplinas e os recursos multimídias oferecidos na plataforma (recursos didáticos) influenciam na decisão em cursar novamente uma disciplina na 
modalidade semipresencial, corroborando com os resultados de Tambosi; Borges; Domingues (2014) e de Beckhauser e Domingues (2017).

Neste sentido, cabem as instituições de ensino o investimento em recursos didáticos que propiciem a implementação dos recursos apontados para atender tais aspectos de qualidade das disciplinas, que são observadas pelos estudantes, e consequentemente a sua decisão em cursar uma nova disciplina na modalidade de ensino a distância. Entende-se que tais recursos destacados, são percebidos pelos discentes por facilitar e incentivar o seu aprendizado, ao mesmo tempo tornando-os mais ativos na construção do conhecimento, favorecendo uma aprendizagem significativa.

Outro aspecto a ser destacado é a atenção das IES quanto a autoavaliação do discente, o qual objetiva avaliar a autonomia, e dedicação a do acadêmico a disciplina cursada, tornando-o capaz de refletir sobre a sua aprendizagem. No entanto a autoavaliação necessita estar alicerçada em questões que envolvam a autonomia e a comunicação na EAD, pois estas bases norteiam a avaliação e fornecem dados para discussões sobre o processo que envolve a modalidade.

Dada a importância do estudo que envolve a autoavaliação e os aspectos relacionados aos recursos didáticos, sugere-se a replicação deste estudo em outras instituições de ensino. Afinal, os resultados encontrados nesta pesquisa não podem ser generalizados, e a sua aplicação e ampliação em outros cursos, com diferentes características contribuiria para o entendimento e amadurecimento teórico e empírico sobre o tema.

\section{REFERÊNCIAS}

ABED - ASSOCIAÇÃO BRASILEIRA DE EDUCAÇÃO A DISTÂNCIA Censo EAD. BR: Relatório Analítico da Aprendizagem a Distância no Brasil 2014 - Curitiba: Ibpex, 2015.

ALVES, L. Educação à distância: conceitos e história no Brasil e no mundo. Revista Brasileira de Aprendizagem Aberta e a Distância - (RBAAD). Recuperado de http://www.abed.org.br/revistacientifica/Revista_PDF_Doc/2011/Artigo_07.pdf.

AMARAL, M. A.; ASSIS, K. K.; BARROS, G. C. Avaliação na EAD: contextualizando uma experiência do uso de instrumentos com vistas à aprendizagem. IX Congresso Nacional de Educação - EDUCERE. III Encontro Sul Brasileiro de Psicopedagogia. 26 a 29 de outubro de 2009.PUCPR.Curitiba-PR, 2009.

ALMRASHDEH, I. A.; SAHARI, N.; MAT ZIN, N. A.; ALSMADI, M. Distance learning management system requirements from student's perspective.Journal of Theoretical and Applied Information Technology, v. 24, n. 1, p. 17-27, 2011. 
ANDERSON, M. A. What's it like to take an online class? Multimedia \& Internet @Schools Magazine, v. 13, n. 4, 2006.

ANDRADE, H.; YANG DU. Student responses to criteria-referenced self-assessment. Assessment \& Evaluation in Higher Education, v. 32, n. 2, p. 159-181, April 2007.

ANDRADE, H.; \& VALTCHEVA, A. Promoting Learning and Achievement Through Self-Assessment, Theory Into Practice, 48:1, 12-19, 2009.

BECKHAUSER, S. P. R.; DOMINGUES, M. J. C. S. Fatores determinantes para cursar novamente uma disciplina na modalidade semipresencial: um estudo de caso com discentes de uma IES no sul do Brasil. $3^{\circ}$ Simpósio Avaliação da Educação Superior, 05 a 06 de setembro de 2017, Florianópolis, SC, 2017.

BELLONI, M. L. Ensaio sobre educação a distância no Brasil. Educação \& Sociedade, ano XXIII, n. 78, abr., 2002.

BERDROW, I.; EVERS, F. T. Bases of Competence: A Framework for Facilitating Reflective Learner-Centered Educational Environments. Journalof Management Education Online First, publishedonFebruary 23, 2010.

BERNARDES, C. C. S. Desenhodidático de materiaisdigitais para educação a distância online.(Dissertação), Universidade Federal de Juiz de Fora. Juiz de Fora/MG, 2012.

BOAS, A. A. V. et al. Tutors and university teachers' perception about quality assurance in distance education: the case of the undergraduate management course in Minas Gerais Brazil. In: GLOBAL ENGINEERING EDUCATION CONFERENCE (EDUCON), 2011, Amman. Anais... Amman: IEEE, 2011.

BRASIL. MEC - MINISTÉRIO DA EDUCAÇÃO. Referenciais de Qualidade para a Educação Superior a Distância. Disponível em:

$<$ http://portal.mec.gov.br/seed/arquivos/pdf/legislacao/refead1.pdf>. Acesso em: 15 out. 2017.

Referenciais de Qualidade para Educação Superior a Distância. 2007.

Disponível em: $<$ http://portal.mec.gov.br/seed/arquivos/pdf/legislacao/refead1.pdf. Acesso em: 15 out. 2017.

Decreto n. 5.622, de 19 de dezembro de 2005. Regulamenta o art. 80 da Lei $\mathrm{n}^{\circ}$ 9.394, de 20 de dezembro de 1996, que estabelece as diretrizes e bases da educação nacional. 2005. Disponível em: <http://www.planalto.gov.br/ccivil_03/_ato20042006/2005/decreto/d5622.htm. Acesso em: 15 out. 2017.

Referenciais de Qualidade para Cursos a Distância. 2003. Disponível em: $<$ http://portal.mec.gov.br/seed/arquivos/pdf/ReferenciaisdeEAD.pdf $>$. Acesso em: 14 dez. 2017.

CARR-CHELLMAN, A.; \& DUCHASTEL, P.The perfect online course. British Journal of Educational Technology, v. 31, n. 3, p.229-241, 2000.

COLLIS, Jill; HUSSEY, Roger. Business research. Basingstoke^ eNH NH: Palgrave Macmillan, 2003. 
ELLIS, J. T.; \& HAFNER, W. Engineering an online course: Applying the 'secrets' of computer programming to course development. British Journal of Educational Technology, v. 34, n. 5, p. 639-650, 2003.

FABRICIO, A. M. et al. Repercussões dos métodos de ensino utilizados pelos docentes de IES pública e privada no desenvolvimento de competências dos seus alunos. VIII

Simpósio de Excelência em Gestão e Tecnologia - SEGeT - AEDB, Resende/RJ, 19 a 21 de outubro de 2011.

FÁVERO, L. P. Análise de dados: modelagem multivariada para tomada de decisões. Rio de Janeiro: Elsevier, Campus, 2009.

FLEMING, D. M. Desenvolvimento de Material Didático para Educação a Distância no contexto da Educação Matemática. São Paulo, 2004. Disponível em: <www.abed.org.br.> Acesso em: 18 fev. 2004.

HADDAD, S; GRACIANO, M. Educação: direito universal ou mercado em expansão. São Paulo em Perspectiva [online], vol.18, n.3, pp.67-77, 2004.

HAIR, Joseph F. Análise multivariada de dados. 6. ed. Porto Alegre: Bookman, 2009.

HENRY, J.; MEADOWS, J.A totally fascinating online course: Nine principles for excellence in teaching online, Can. J. Learn. Technol., p. 177-179, 2008.

HOPPER, K. B., \& HARMON, S. W. A multiple-case study of exemplary courses internet. Education at a Distance [Online], 2000. Retrieved January 17, 2007 from http://www.usdla.org/html/journal/SEP00_Issue/story04.htm

MALLMANN, E. M.; CATAPAN, A. H. Materiais didáticos em educação a distância: gestão e mediação pedagógica. Linhas, Florianópolis, v. 8, n.2, p. 63 - 75, jul / dez 2007.

MANCEBO, D; VALE, A. A.; MARTINS, T. B. Políticas de expansão da educação superior no Brasil: 1995-2010. Revista Brasileira de Educação, Rio de Janeiro, v. 20, n. 60, p. 31-50, jan./mar. de 2015 .

MARCUZZO, M. M. V.; GUBIANI, J. S.; LOPES, L. F. D.; REGIO, M. L. S. A satisfação dos alunos de educação a distância: um estudo de caso aplicado em nível de graduação e pós-graduação de uma universidade federal. XV COLÓQUIO INTERNACIONAL DE GESTÃO UNIVERSITÁRIA - CIGU Desafios da Gestão Universitária no Século XXI Mar del Plata - Argentina 2, 3 e 4 de dezembro de 2015.

MARCHESAN, T. M., SOUZA, A. M. Avaliação do processo de ensino docente pelo discente: Uma abordagem multivariada para qualidade. Anais do XXVI Encontro Nacional de Engenharia de Produção. Fortaleza/CE, 2006.

MARCHETI, A. P. C. et al. Educação à distância: diretrizes e contribuições para a implantação dessa modalidade em instituições educacionais. Revista digital da CVARICESU. v. 3, n. 9, Jul, 2005.

MONTIEL, J. M., AFFONSO, S. B., RODRIGUES, S. \& QUINELLATO, E. Escala de percepção discente do EAD (EPD-EAD). Avaliação Psicológica, v. 13, n. 3, p. 359-369, 2014. 
NUNES, R. C. A avaliação em educação a distância é inovadora? - uma reflexão. 160 Congresso Internacional Abed de Educação a Distância, Foz do Iguaçu, 2010. Est. Aval. Educ., São Paulo, v. 23, n. 52, p. 274-299, maio/ago, 2012.

PINHO, D. S. Material didático em um ambiente virtual de aprendizagem. (Dissertação), Universidade Católica do Rio Grande do Sul. Porto Alegre/RS, 2008.

POSSOLLI, G. E.; CURY, P. Q. Reflexões sobre a elaboração de materiais didáticos para educação a distância no Brasil. IX Congresso Nacional de Educação - EDUCERE. III Encontro Sul Brasileiro de Psicopedagogia, 26 a 29 de outubro de 2009. PUCPR.

PRIMO, L. Autoavaliação na Educação a Distância uma alternativa viável. Anais do XX VIII Congresso da SBC. WIE - Workshop sobre Informática da Escola. 12 a 18 junho, 2008, Belém do Pará, PA.

PINTRICH, P. The role of goal orientation in selfregulatedlearning.In M. Boekaerts, P. Pintrich,\& M. Zeidner (Eds.), Handbook of self-regulation (p. 452-502). San Diego, CA: Academic Press, 2000.

PUNHAGUI, G. C.; SOUZA, N. A. A autoavaliação para a autorregulação da aprendizagem em língua estrangeira: apontamentos. Cadernos de Educação | FaE/PPGE/UFPel. Pelotas [v.42], p. 199 - 222, 2012.

ROSS, J. A. The Reliability, Validity, and Utility of Self-Assessment. Practical Assessment, Research \& Evaluation. Volume 11 Number 10, November 2006.

SARMENTO, D. F.; BARBOSA, D. N. F.; MANGAN, P. K. V. A dimensão didáticopedagógica na Educação a Distância: um enfoque na prática docente na disciplina de, Psicologia da Educação. CINTED-UFRGS - Novas Tecnologias na Educação, V. 6 No 1, Julho, 2008.

SIEBER, J. E. Misconceptions and Realities About teaching online. Science and Engineering Ethics, v. 11, p. 3, 2005.

SILVEIRA, T. S. Política de inclusão no ensino superior na modalidade EAD nas universidades privadas. (Tese de Doutorado), Universidade do Vale do Itajaí - UNIVALI. Itajaí, SC, Brasil, 26 de fevereiro de 2015.

SCHENATZ, B. N.; BORGES, M. A. F. O ensino de métodos e técnicas de pesquisa em educação mediado pelo uso das TIDC: contribuições das comunidades colaborativa de aprendizagens em EAD on-line. V Seminário Internacional de Educação a Distância. CAED, UFMG, 2 a 4 de setembro de 2013.

SOUZA, R. P.; MOITA, F. M. C. S. C.; CARVALHO, A. B. G. Tecnologias Digitais na Educação. EDUEPB-Universidade Estadual da Paraíba, Campina Grande/PB, 21 ed. CDD, p. 276,2011 .

SPUDEIT, D. F. A. O.; VIAPIANA, N; VITORINO, E. V. Bibliotecário e educação a distância (EAD): mediando os instrumentos do conhecimento. Revista ACB:

Biblioteconomia em Santa Catarina, Florianópolis, v. 15, n. 1, p. 54-70, jan./jun. 2010. 
TAMBOSI, S. S. V.; BORGES, G. R.; DOMINGUES, M. J. C. S. A influência da qualidade da disciplina, do AVA e da dedicação do aluno na propensão em cursar novamente uma disciplina a distância. Anais... XIV Colóquio de Gestão Universitária (CIGU), Florianópolis, 3 a 5 de dezembro, 2014.

TAROUCO, Liane. Educação a distância: Tecnologias e métodos para implantação e acompanhamento. In: Workshop Internacional Sobre Educação Virtual - WISE'99, 1999, Fortaleza. Anais. Fortaleza: WISE, p. 344-359, 1999.

VARGAS, Y. H.; SOLÍS, I. I.; ESPINOSA, J. C. M.; OLIVARES, F. M. Distance Learning vs on Site Learning “A Comparative Study in a Public University in Mexico".Education, v. 6, n. 3, p. 69-74, 2016,

VIDAL, O. F.; MERCADO, L. P. L. Reflexões teóricas acerca da produção de material didático para educação a distância. ESUD 2014 - XI Congresso Brasileiro de Ensino a Distância, Florianópolis/SC, 05 - 08 de agosto de 2014. UNIREDE.

VITORINO, E. V. Metodologia de ensino via educação a distância (EaD) integradora e colaborativa para o ensino superior, baseada na percepção dos alunos (MAPICes). (Tese de Doutorado), Universidade Federal de Santa Catarina, SC, Brasil, 2014.

WHITE, C. Students and faculty Respond to online distance courses at Grant MacEwan Community College. Learn Online, v. 27, n. 9, 2000.

ZERBINI, T.;\& ABBAD, G. Estratégias de aprendizagem em curso a distância: validação de uma escala. Psico-USF, v. 13, n.2, p.177-187, 2008.

ZIMMERMAN, B.; \& SCHUNK, D. Self-regulating intellectual processes and outcomes: A social cognitive perspective. In D. Dai \& R. Sternberg (Eds.), Motivation, emotion, and cognition: Integrative perspectives on intellectual functioning and development (p. 323-349). Mahwah, NJ: Lawrence Erlbaum Associates, 2004. 